\title{
The Effect of Mixing and Curing Sea Water on Concrete Strength at Different Ages
}

\author{
Qingyong Guo ${ }^{1}$, Lei Chen ${ }^{1}$, Huijian Zhao ${ }^{1}$, Jorge Admilson ${ }^{1}$, and Wensong Zhang ${ }^{2}$ \\ ${ }^{1}$ College of Aerospace and Civil Engineering, Harbin Engineering University,Harbin 150001, China \\ ${ }^{2}$ General Research Institute for Nonferrous Metals, Beijing 100088, China
}

\begin{abstract}
In the research, the effects of sea water for mixing, curing on the gain in strength of different grades of concrete was investigated. A total of 192 concrete cubes were tested for their compressive strength. The study shows that sea water affects the rate of gain in strength of concrete when used for mixing or curing. The strength of concrete made by using sea water was observed to be decreased by about $15 \%$ as compared to the similar concrete specimens made and cured with fresh water at 90 days. The concrete with higher strength showed poorer resistance against strength deterioration as compared to the lower strength concrete which used sea water for curing. And the concrete made with sea water decreased the stability of concrete properties.
\end{abstract}

\section{Introduction}

The United Nation estimates that till 2050 the world will get an additional population of about 2.5bilion [1], with the largest growth in developing countries that have experienced in water crisis. In addition more than half population will not be able to get enough drinking water. Increasing infrastructure development is in line with the needs of clean water every year, where sea water has not been used for such things for that reason. Study of fresh water savings is very seriously needed. The use of sea water, the percentage is $97 \%$ from the total water on the earth, is absolutely necessary.

In coastal areas, there has always been a deficiency of fresh water as the available water is affected by sea salts. So it is difficult to deliver fresh water for construction works in such location. Also it is economical to use sea water that is available near the construction site instead of potable water to be transported from other areas sources. But sea water contains large amount of sea salts, which may have unfavorable effect on the properties of concrete[2]. Till now, there are many researchers investigated on the strength behavior of concrete made with plain as well as sea water and also to be exposed in marine condition[37].

Although the existing literature and codes of practice reveal the effect of mixing and curing of sea water on durability of concrete, it still remains an area requiring further study and research particularly of the use of structural concrete in marine environment.

\footnotetext{
*Corresponding author: qingyong622@126.com
} 
The main purpose of this research is to investigate the potential of replacing the fresh water by salt sea water in concrete mixtures and identify its mechanical behavior when mixed and cured with salt sea water. So in this study, the strength behavior of concrete made and cured with sea water on the gain in strength of different grades of concrete is investigated.

\section{Experimental program}

The experimental program was planned to investigate the effect of sea water for mixing and curing on the gain in strength of concrete at different ages. This study includes determination of compressive strength (up to 90 days) of 192 specimens made and cured by using plain water as well as sea water.

\subsection{Materials used}

The details of various materials used in the experimental investigation are as following:

(1) Cement: The cement used was Ordinary Portland Cement (OPC) 42.5 grade. It was stored under dry condition, free of lumps and in conformity with GB/T50081-2011[8].

(2) Aggregates: The coarse aggregate used was crushed stone with a size of $15-20 \mathrm{~mm}$. The fine aggregate used was medium sand having a particle size greater than $0.25 \mathrm{~mm}$ and a mass exceeding $50 \%$ of the total mass. Fineness modulus was in the range of 3.0-2.3.

(3) Mixing Water: The water used was fresh and sea water, the fresh water was gotten from the tap in the laboratory, as well was the sea water gotten but mixed with sea salt.

\subsection{Test layout and procedure}

(1) Concrete quality: Four different groups of concrete, namely concrete A, B, C and D were used. Relevant information of the concrete mixes is given in table 1, where each group were mixed and cured in fresh water (FF), mixed and cured in sea water (SS), mixed with fresh water and cured in sea water (FS), and mixed with sea water and cured with fresh water (SF). Sea water means water mixed with salt, and fresh water means tap water or plain water.

(2) Exposure period: Test specimens were tested periodically after specified curing periods of 90 days in fresh water as well as sea water.

(3) Size of specimen: Concrete cube of $100 \times 100 \times 100(\mathrm{~mm})$ was used for measuring the compressive strength determined according to GB/T50081-2011[8].

(4) Curing environment: A total of 192 concrete cubes were cast in the laboratory. And then the specimens were kept at $22^{\circ} \mathrm{C}$ temperature for 24 hours. After demolding, all specimens were made and cured as per program schedule indicated in table 1.

Table 1. Details of Concrete Mixes

\begin{tabular}{c|c|c|c|c|c|c}
\hline $\begin{array}{c}\text { Concrete } \\
\text { Category }\end{array}$ & $\begin{array}{c}\text { W/C } \\
\text { Ratio }\end{array}$ & OPC & $\begin{array}{c}\text { Fine } \\
\text { aggregate }\end{array}$ & $\begin{array}{c}\text { coarse } \\
\text { aggregate }\end{array}$ & $\begin{array}{c}\text { Mixing and curing } \\
\text { mode }\end{array}$ & $\begin{array}{c}\text { Exposure } \\
\text { Periods } \\
\text { (Days) }\end{array}$ \\
\hline A & 0.50 & 1 & 1.5 & 3 & FF & 7 \\
\hline B & 0.45 & 1 & 1.5 & 3 & FS & 14 \\
\hline C & 0.50 & 1 & 2 & 4 & SF & 28 \\
\hline D & 0.45 & 1 & 2 & 4 & SS & 90 \\
\hline
\end{tabular}

Note:FF-Concrete cast and cured with fresh water; SF - Concrete cast with sea water and cured with fresh water; FS - Concrete cast with fresh water and cured with sea water; SS - Concrete cast and cured with sea water. 
Compressive strength test was performed on the concrete cubes at the curing age of 7 , 14, 28 and 90 days using the compressive testing machine. After the specific period of exposure, the cubes specimen were compressed at uniform rate $4.0 \mathrm{kN} / \mathrm{sec}$ (without shock) until failure occurred[9].

\section{Test results and discussion}

The result was the average strength of three standard-cured specimens made from the same concrete sample and tested at the same age. The compressive strengths at the age of 7,14 , 28 and 90 days for all groups were represented in table 2 and figures below.

\subsection{Variation of compressive strength with ages}

According to the variation of compressive strength in Fig. 1 to Fig. 4, it was observed that the concrete made with sea water (SS and SF) showed rapid increase in early strength, compared with the concrete made with fresh water(FF and FS) at 7 days of curing. The early increase in strength of concrete SS and SF are basically due chlorides contains in sea water that tends to accelerate the setting of cement and to improve the strength. While the rate of gain in strength of sea water mixed concrete (SS and SF) and sea water mixed and fresh water cured (SF) are observed to be less than that of fresh water mixed concrete (FF and FS) at $14 \mathrm{~d}, 28 \mathrm{~d}$ and $90 \mathrm{~d}$, due to leaching out of soft hydration product or the sulphates contains in sea water that retard the setting of cement.

Table 2. Average compressive strength

\begin{tabular}{c|c|c|c|c|c}
\hline \multirow{2}{*}{$\begin{array}{c}\text { Concrete } \\
\text { mix }\end{array}$} & \multirow{2}{*}{$\begin{array}{c}\text { Concrete } \\
\text { designation }\end{array}$} & \multicolumn{4}{|c}{ Compressive strength (MPa) } \\
\cline { 2 - 6 } & 7 days & 14 days & 28 days & 90 days \\
\hline \multirow{4}{*}{ A } & FF & 39.47 & 45.18 & 47.17 & 59.31 \\
\cline { 2 - 6 } & FS & 42.05 & 46.20 & 49.79 & 54.98 \\
\cline { 2 - 6 } & SF & 39.10 & 41.47 & 41.40 & 45.38 \\
\cline { 2 - 6 } & SS & 38.03 & 43.63 & 46.14 & 53.31 \\
\hline \multirow{4}{*}{ B } & FF & 41.17 & 46.12 & 54.33 & 65.25 \\
\cline { 2 - 6 } & FS & 41.30 & 46.46 & 49.98 & 62.51 \\
\cline { 2 - 6 } & SF & 43.66 & 46.46 & 45.37 & 57.14 \\
\cline { 2 - 6 } & SS & 42.18 & 45.51 & 48.32 & 54.64 \\
\hline \multirow{4}{*}{ C } & FF & 36.60 & 48.15 & 49.02 & 62.00 \\
\cline { 2 - 6 } & FS & 41.32 & 47.42 & 49.70 & 56.05 \\
\cline { 2 - 6 } & SF & 40.99 & 43.24 & 41.55 & 53.64 \\
\hline & SS & 40.98 & 44.11 & 46.46 & 56.63 \\
\hline & FF & 46.24 & 47.04 & 59.09 & 66.95 \\
\cline { 2 - 6 } & FS & 42.32 & 49.13 & 58.56 & 63.20 \\
\cline { 2 - 6 } & SF & 37.85 & 46.11 & 44.98 & 46.36 \\
\cline { 2 - 6 } & SS & 44.79 & 52.37 & 50.69 & 57.37 \\
\hline
\end{tabular}

It is shown that the sea water has significant effects on the gain of concrete strength with curing age. Sea water for mixing and curing concrete results in around $15 \%$ of strength 
loss compared to the concrete made and cured with fresh water. Fresh water mixed and sea water cured concrete also shows losses in strength comparing to the control batch (FF) around $7 \%$.

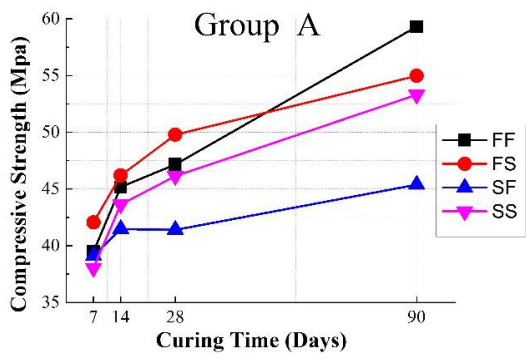

Fig. 1. Compressive strength for group A

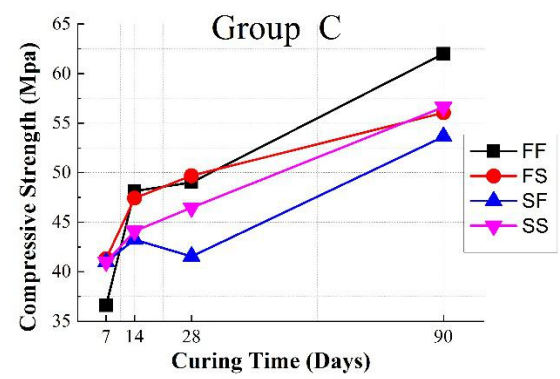

Fig. 3. Compressive strength for group $\mathrm{C}$

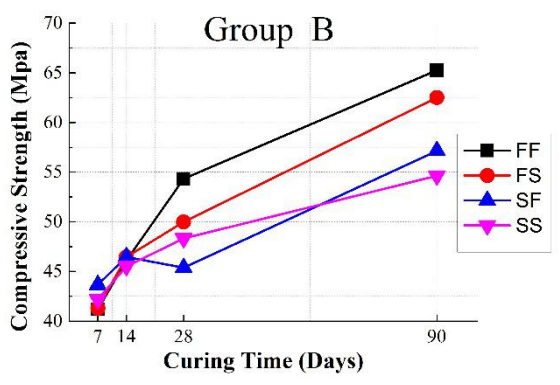

Fig. 2. Compressive strength for group B

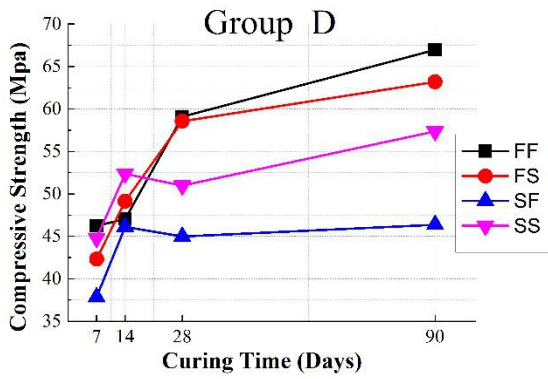

Fig. 4. Compressive strength for group D

Comparing the four types of concrete designation FF and SS above, it is seen that, strength losses of concrete is observed to vary with the grade of concrete. At curing age 28 days, the overall losses of strength of concrete SS are observed to $1.03 \mathrm{Mpa}$ for group A, $2.56 \mathrm{MPa}$ for group $\mathrm{C}, 6.01 \mathrm{MPa}$ for group $\mathrm{B}$ and $8.40 \mathrm{MPa}$ for group $\mathrm{D}$ compared to the concrete FF. Then at curing age 90 days, the losses are observed $5.37 \mathrm{MPa}$ for group $\mathrm{C}$, $6.0 \mathrm{MPa}$ for the group $\mathrm{A}, 9.58 \mathrm{MPa}$ for group $\mathrm{D}$ and $10.61 \mathrm{MPa}$ for group $\mathrm{B}$. Among all the concretes studied, Group D and B are found to be mostly affected by the sea water. The possible cause for strength deterioration may be due to dissolution of the compounds rich in lime and the formation of expansive compounds as a result of chloride and sulfate attack of sea water.

So it can be concluded that relatively higher strength concrete showed poorer resistance against strength deterioration as compared to lower strength concrete. In opposition, sea water mixed and cured concrete shows around 15\% higher strength loss as compared to fresh water mixed and cured concrete.

\subsection{Variation of relative intensity with concrete grade}

In order to be able to more closely reflect the law of compressive strength versus age, the relative compressive strength at different ages of four concrete batches were calculated using the ratio of strength at each age with the intensity of 28 days. As seen in the relative intensity graphic as shown in Fig. 5 to Fig. 8 below, the four concrete designation graphics assembled in one graphic for four concretes designation are dispersed around the logarithm 
line of the function equation $\mathrm{y}$, taking the concrete designation FF as standard result, which according to the variable $x=f_{n} / f_{28}$. The correlation coefficients $\left(R^{2}\right)$ were calculated whether the closer it gets to 1 the better it is.

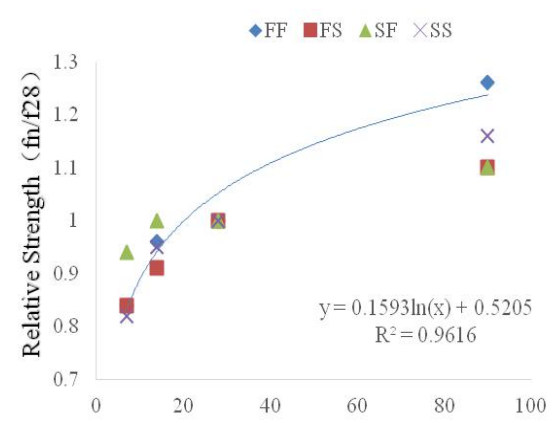

Fig. 5. Relative intensity for group A

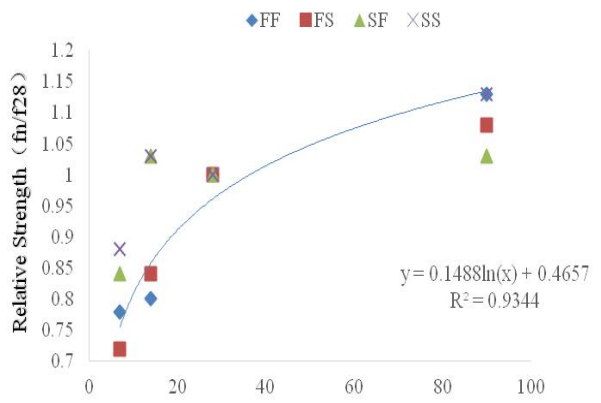

Fig. 7. Relative intensity for group C

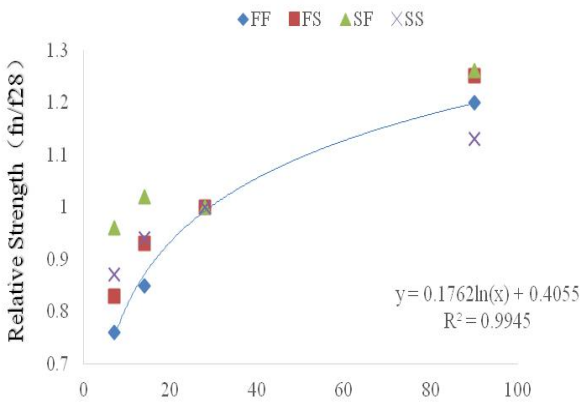

Fig. 6. Relative intensity for group B

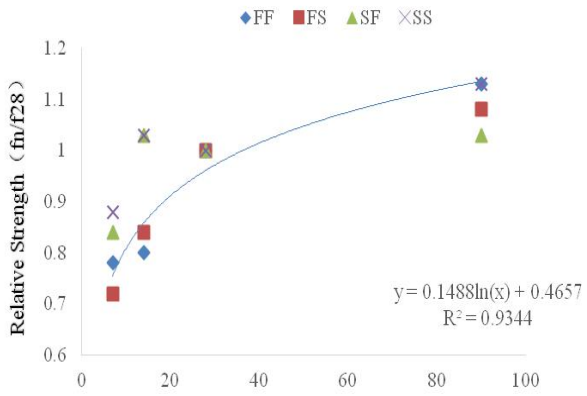

Fig. 8. Relative intensity for group D

It is found that the concrete made with sea water (SS and SF) showed bigger dispersion than that of the concrete made with fresh water (FF and FS). It means that the sea water decreases the stability of concrete properties. Therefore for application some precautions and analysis of the effect of sea water in mixing and curing concrete has to be taken.

\section{Summary}

The results of the research investigated on four different grades of concrete made with fresh and sea water, cured in fresh water as well sea water over a period of 90 days for compressive strength have been analyzed. The following conclusions are drawn:

(1) Sea water affects the gain in strength of concrete when used for mixing and curing. It shows some increases at the early strength but ultimately decrease the strength.

(2) Concrete specimens made with fresh water and cured with sea water shows a loss in strength of around 7\% whereas concrete specimens made and cured with sea water showed loss in strength of around $15 \%$ as compared to the similar concrete specimens made and cured with fresh water at age 90 days.

(3) Among the four grades of concrete studied, the higher grade concrete B showed around $9 \%$ higher strength loss as compared to the other grades of concrete A, C and D when used sea water for mixing and curing concrete. And the higher strength concrete showed poorer resistance against strength deterioration as compared to the lower strength when used sea water for curing. 
This research was financially supported by Natural Science Foundation of Heilongiiang Province of China(NO: E201415) and the Fundamental Research Funds for the Central Universities of China (No.GK2020260143).

\section{References}

1. G. Tchobanoglous, F. L. Burton, and H. D. Stensel. Wastewater Engineering: Treatment and Reuse(4th ed) ( Metcalf \& Eddy Inc., New York,2003)

2. Ghorab H. Y. Cement and Concrete Research. 19,868 (1989)

3. Olutoge, F. Adeyemi, Amusan, G. Modupeola.International Journal of Engineering Science Invention. 3, 23 (2014)

4. Akinkurolere O. O., Jiang C, Shobola O. M. Journal of Engineering and Applied Sciences. 2 ,412 ( 2007)

5. H.K. Liu. N.H. Tai. W.H. Lee. Composites Science and Technology. 62,2131 (2002)

6. Uddin, T., Hidenori, H. and Yamaji, T. Cement and Concrete Research. 34, 593 (2004)

7. Zaher, K. and Shihada, S. Journal of the Islamic University of Gaza.11,156 (2003)

8. Chinese Standard. Common Portland Cement standard(Standards Press of China, Beijing, China, 2015)

9. Chinese Standard. Standard for technical requirements and test method of flexural strength (Standards Press of China, Beijing, China, 2011) 